\title{
Boolean operations of STL models based on loop detection
}

\author{
K.-B. Guo • C.-J. Wang $\cdot$ L.-C. Zhang $・$ S.-H. Huang
}

Published online: 2 December 2006

(C) Springer-Verlag London Limited 2006

The originally published reference list of this article unfortunately contained a mistake.

The online version of the original article can be found at http:/dx.doi. org/10.1007/s00170-006-0487-5.

K.-B. Guo $(\bowtie) \cdot$ C.-J. Wang $\cdot$ L.-C. Zhang $\cdot$ S.-H. Huang

State Key Laboratory of Plastic Forming Simulation and Die and Mould Technology,

Huazhong University of Science and Technology,

Wuhan 430074, People's Republic of China

e-mail: guokb@sohu.com
Incorrect reference:

1. Kai CC, Jacob GG, Mei T (1997) Interface between CAD and rapid prototyping systems. Part 1: a study of existing interface. Adv Manuf Technol 13:566-570

Correct reference:

1. Chua CK, Gan JGK, Tong M (1997) Interface between CAD and rapid prototyping systems. Part 1: a study of existing interface. Adv Manuf Technol 13:566-570 